\title{
Biosaintifika
}

Journal of Biology \& Biology Education

http://journal.unnes.ac.id/nju/index.php/biosaintifika

\section{Agronomic Characterization of Wheat Mutants (Triticum aestivum) of M3 Generation Planted in Sukabumi}

\author{
${ }^{\square}$ Laela Sari $^{1}$, Agus Purwito ${ }^{2}$, Didy Sopandie ${ }^{2}$, Ragapadmi Purnamaningsih ${ }^{3}$, Enny Su- \\ darmonowati $^{1}$
}

DOI: 10.15294/biosaintifika.v8i3.6612

${ }^{1}$ Research Center for Biotechnology, Indonesian Institute of Sciences, Bogor, Indonesia ${ }^{2}$ Departement of Agronomy and Horticulture, Bogor Agricultural University, Bogor, Indonesia ${ }^{3}$ Indonesian Center for Agricultural Biotechnology \& Genetic Resources, Ministry of Agriculture, Bogor, Indonesia

\section{History Article}

Received 25 July 2016 Approved 14 October 2016 Published 24 December 2016

\section{Keywords:}

characterization; agronomy; wheat mutant; medium land

\begin{abstract}
The purpose of this study was to identify the selection criteria to obtain a superior mutant derived from the wheat plants of such varieties as Dewata, Selayar and Alibey, adaptive in medium land. The analysis of agronomic growth characters showed a significantly effect on a growth percentage of the initial growth (8 mutants), flowering time (1 mutant), panicle stem length (15 mutants), number of panicles ( 7 mutants), the number of grains per panicle ( 8 mutants), grain weight observed ( 8 mutants), grain weight per genotype (6 mutants), leaf area ( 2 mutants) and leaf greenness ( 5 mutants). The effects on the characters of ripe time, harvest, panicle length and plant height were not significant. The mutants of Dewata, Selayar and Alibey could be selected based on the characters of panicle stem length, number of grains per panicle and grain weight per observation because these characters generated more mutants than the other characters. The correlation analysis between the characters of growth and yield components of wheat mutants showed that the number of grains per panicle was positively correlated with the grain weight observed, while the length of panicle stem was positively correlated with grain weight per genotype, number of panicles and leaf area. Hopefully some mutants produced could adapt to the tropical medium land, thus adding to the diversity of wheat germplasm in Indonesia, thereby reducing the import of wheat to Indonesia.
\end{abstract}

\section{How to Cite}

Sari, L., Purwito, A., Sopandie, D., Purnamaningsih, R. \& Sudarmonowati, E. (2016). Agronomic Characterization of Wheat Mutants (Triticum aestivum) of M3 Generation Planted in Sukabumi. Biosaintifika: Journal of Biology \& Biology Education, 8(3), 352-360.

(C) 2016 Universitas Negeri Semarang $\square$ Correspondence Author:

Jl. Raya Jakarta, Bogor Km. 46 Cibinong, 16911, Bogor

E-mail: laelasari@yahoo.com
p-ISSN 2085-191X

e-ISSN 2338-7610 


\section{INTRODUCTION}

Wheat is a subtropical plant, but with certain efforts it can be cultivated in tropical regions in Indonesia. Wheat crop was introduced into Indonesia around 1784, planted on limited areas in the mountains of Java and Timor. However, because the climate in Indonesia is not suitable for growing wheat plants and efforts to develop the cultivation of wheat are not a priority, the wheat crop has not been widespread (Wiyono, 1980; Carver, 2009). Wheat varieties that have been released in Indonesia come from the introduction and no genotype has been specifically selected for agro-climatic suitability in Indonesia. Results of multi-location adaptation trials in various regions indicated that the wheat plants could grow and produce high yields but it is confined to the plateau above $1000 \mathrm{~m}$ asl in Indonesia (Dahlan et al., 2003).

Wheat consumption in Indonesia lately has increased rapidly so that wheat imports in 2012 reached 7.4 million tons (Aptindo, 2012). The development of such industry as instant noodles, bread and canned biscuits as well as the high consumption of wheat flour in Indonesia, especially in the urban areas, has encouraged higher grain imports. Therefore, it is necessary to identify genotypes that can adapt well to the tropical medium land from different genetic sources of wheat in the world.

One way to obtain wheat genotypes adaptive to tropical regions is by a mutation technique using physical and chemical mutagens. The physical mutagens which are often used are the ionizing of alpha, beta, and gamma rays, while the chemical mutagens commonly used are colchicine and EMS (Van Harten, 1988). The use of EMS to increase the occurrence of mutation has been conducted, such as to produce wheat genotypes which are fast to flower and have their grains ripen, and obtain the $\mathrm{M} 3$ wheat plants that have high productivity (Sakin et al., 2002; Vismanathan \& Reddy 1996).

The mutation induction technique was considered suitable to get the plant genetic diversity whose genetic resource availability is poor. In Indonesia, wheat plants are classified as the plants whose source of genetic diversity is very low, making it hard to obtain a new character which is superior with a hybridization technique (Micke \& Donini, 1993). The unavailability of high-yielding varieties of wheat has made wheat unable to compete with the commodities that are often grown at higher lands such as vegetables and other horticultural crops that have higher economic values.

The mutation technique followed by the selection of high temperature resistance in vitro has been carried out on potato and garlic plants and has successfully obtained a high temperature tolerant mutants (Das et al., 2000). The plants as regeneration results from induced mutation and selection in vitro are expected to be tolerant to high temperatures and can adapt to the lowlands. A gene mutation that occurs in the direction of a positive nature and to be passed on to the next generation is the desired mutation by plant breeders in general (Soeranto, 2003).

Based on the results of the previous studies, it was reported that wheat of Nias and Timor varieties could produce 2 tons / ha, while varieties of Dewata and Selayar could produce more than 2 tons / ha in the highlands (1000 m asl) in Indonesia (Dahlan et al., 2003). The varieties that have been released in Indonesia are only suitable for planting in the highlands. The varieties that are suitable for the medium land have not been developed. Available land in the highlands is very limited and has been used for the cultivation of vegetables that have a higher economic value. If there is an adaptive variety of wheat in the medium land, there are opportunities to grow wheat in the rotation of rice-rice-wheat in the medium land. Rice fields which are fallow for four months are still available from July to October, which might be used for wheat planting. Wheat cultivation in a tropical environment at an altitude of $>$ $1000 \mathrm{~m}$ asl worked out well such as in the areas of Tosari, Banjarnegara, Salatiga, Malino, Sinjai and Padang. However, the areas of wheat development in these areas are very limited, because wheat crop is only used as sidelines of horticultural crops that are more economical. Therefore, it is necessary to carry out a long-term research program for the development of wheat in Indonesia. The program is a joint research to obtain highyielding varieties of wheat in the lowlands. The research focus is on breeding to produce wheat varieties that are adaptive to tropical lowlands.

Plant breeding at stress environment requires superior crops that can adapt to the stress condition. The development of wheat in lowland environments can be achieved through the level of adaptation of plants to abiotic stress, and the improvement of yield potential. These factors are interrelated in obtaining superior crops that can yield high. According to Soepandi (2013) crop improvement can be achieved if the morphology and physiology of the plant have already been known from characters that support it, such as photosynthesis, growth and crop production. 
This study aimed to determine the characters of morphology and agronomy and to identify the selection criteria to obtain a superior mutant derived from the wheat plant of M3 generation adaptive in medium land.

\section{METHOD}

The study was conducted in the BB-BIOGEN experimental garden, Sukabumi, in the medium land $\pm 450 \mathrm{~m}$ above sea level from April 2013 to September 2013. The temperature in the experimental garden ranged from $29-34^{\circ} \mathrm{C}$. The material studied consisted of 25 mutan genotypes (out of 144 mutant genotypes) of M3 generation as a result of EMS treatement and three control plants as comparison, namely, Dewata, Selayar, and Alibey (Sari et al., 2014). This experiment used Augmented Design, with six plots and the distance of each plot was $50 \mathrm{~cm}$. The area per plot was $7 \times 1.8 \mathrm{~m}$ with a spacing of $20 \times 25 \mathrm{~cm}$. Each panicle per genotype was planted in one row. Observations made on several morphologi$\mathrm{cal}$ and agronomic traits were conducted in several steps: 1) observations of agronomic characters of M3 wheat generation, 2) characterization of the flag leaf area and leaf greenness.

This study was conducted to examine the M3 genotypes in medium plains. In selected M3 seeds (M2 selection result), there were $144 \mathrm{mu}$ tant genotypes and 3 control plants as comparison (Dewata, Selayar, Alibey) planted per panicle for each genotype in a single row. In each plot was planted with 24 mutant genotypes and 3 control plants, so that each plot contained 27 lines. In every eight mutant genotypes, there was a line of control plants planted, up to 24 mutant genotypes, so that there were 3 lines of controls in all. First of all, the soil was treated with the addition of compost $250 \mathrm{~kg} /$ ha and $125 \mathrm{~kg}$ rice husk / ha. The plants were fertilized with $200 \mathrm{~kg}$ of urea / ha, $150 \mathrm{~kg} \mathrm{SP} 36$ / ha and $100 \mathrm{~kg} \mathrm{KCl} /$ ha 14 days after planting (dap), and the second fertilization was with $150 \mathrm{~kg}$ urea / ha 30 days after planting. Before planting, the seeds were given insecticide called Sevin and at the time of planting, the planting hole was given Carbofuran. Weeding is done twice: during the second fertilization and at the generative growth phase.

In M3 plants, rows of superior plants were identified, and then some of the best plants were selected from each variety in each line to test the agronomic performance. Observations of M3 plants were to find out their agronomic characters, namely, the percentage of early life (\%),flowering age (days), ripening age (days), harvest age (days), long stem panicle $(\mathrm{cm})$, panicle stem length $(\mathrm{cm})$, plant height $(\mathrm{cm})$, number of tillers, number of panicles, number of grains per panicle, grain weight per panicle (g), seed weight per genotype (g), leaf area $(\mathrm{cm})$, and leaf greenness.

Leaf area was measured when the flag leaf had opened up perfectly and had shown a panicle, about 2.5 months old. The tool used to measure the leaf area is leaf area meter.

Leaf greenness can be measured using SPAD-502 chlorophyll meter. Chlorophyll meter is used to measure the percentage of the intensity of leaf greenness, especially when the crop enters the generative phase and the flag leaf has fully developed. The figure readable in the chlorophyll meter showed the total amount of chlorophyll. The higher the legible figure is in the chlorophyll meter, the higher percentage of the chlorophyll in the leaf.

Data analysis was performed using a design enlargement (Augmented Design) and the correlation analysis between the characters. According to Petersen (1994), in Augmented Design before the data was analyzed, it was necessary to make adjustments for differences in each row. The adjustments are based on the average value of the putative mutant genotype in a particular row and the average value of genotype controls throughout the experiment. To estimate the error standard, it was used Middle Square of Expectation / MSE / Middle Square of Error.

The value of Middle Square of Expectation was derived from the analysis of variance calculation. Furthermore, the error standard was used to estimate the value of LSI (Least Significant Increase). LSI value was used to compare between control varieties and M3 population. Data mutant M3 analyzed the correlation between characters using SAS 9.1.

\section{RESULTS AND DISCUSSION}

During the research in the experimental garden of BB-BIOGEN Sukabumi ( $\pm 450 \mathrm{~m}$ asl), the temperature ranged from $29.00-34.00^{\circ} \mathrm{C}$ (Table 1). This indicated that the temperature at the site of the experimental garden was higher than $25^{\circ} \mathrm{C}$, which is the threshold temperature for the wheat crop. Threshold is the temperature which is one degree above the threshold value which causes the growth and development of the plant is not functioning (Sopandie, 2013). The temperature rise of $1^{\circ} \mathrm{C}$ may inhibit the wheat growth. In the meantime, every drop in elevation causes an increase in air temperature. The increase in temperature can lead to stress during the growth 
and development of wheat plants (Handoko 2007). According to Wiyono (1980); Van Ginkel and Villareal (1996), wheat requires a temperature of about $15-25^{\circ} \mathrm{C}$ to grow well and cannot grow well in warm areas with high temperatures. 25 out of 144 genotypes tested were randomly selected based on the percentage of wheat early growth and panicle stalk length (Table 2). The genotypes elected were 16 Dewata, 4 Selayar and 5 Alibey, or as follows: Dw-1-22-3, Dw-2-131, Dw-2-13-2, Dw-2-19-3, Dw-1-17-1, Dw-1-211, 2Dw-5-21-1, 2Dw-5-24-1, 2Dw-5-26-1, 2Dw5-28-1, 2Dw-5-29-1, 2Dw-6-3-1, 2Dw-6-5-1, 2Dw-6-16-1, 2Dw-6-17-1, 3Dw-6-27-1, Ab-1-7-2,
Ab-2-14-1, Ab-3-3-1. Ab-3-3-2, Ab-3-16-1, S1-214-2, S1-3-1-1, S1-3-2-1, and S1-3-2-2.

Table 1. Temperature range during the research in the experimental garden of BB-BIOGEN Sukabumi (2013).

\begin{tabular}{lllll}
\hline Month & April & May & June & July \\
\hline Temperature $\left({ }^{\circ} \mathrm{C}\right)$ & 30 & 29 & 34 & 31 \\
\hline
\end{tabular}

The results of variance analysis of augmented agronomic growth characters showed that there was a significant effect higher than the control plants with mutants on the percentage

Table 2. Characteristics of growth on wheat agronomic mutants Dewata, Selayar and Alibey are in planting in BB-BIOGEN experimental garden, Sukabumi, in 2013 ( $\pm 450 \mathrm{~m}$ asl).

\begin{tabular}{llllllll}
\hline Genotipe & PE & FA & RA & HA & LSP & PSL & PH \\
\hline Dewata (K) & 46.86 & 77.60 & 97.12 & 102.77 & 11.08 & 13.74 & 73.63 \\
Dw-1-22-3 & $53.88^{*}$ & 38.89 & 59.02 & 68.80 & $11.91^{*}$ & 8.71 & 53.38 \\
Dw-2-13-1 & 39.33 & 43.29 & 64.02 & 73.80 & $12.91^{*}$ & 9.21 & 46.08 \\
Dw-2-13-2 & 40.07 & 40.89 & 59.02 & 68.80 & $14.21^{*}$ & 8.91 & 55.08 \\
Dw-2-19-3 & $73.40^{*}$ & 40.29 & 60.72 & 70.50 & 10.91 & 8.21 & 52.38 \\
Dw-1-17-1 & 42.19 & 42.59 & 64.02 & 73.80 & $14.41^{*}$ & 8.91 & 53.38 \\
Dw-1-21-1 & $59.33^{*}$ & 40.29 & 64.02 & 73.80 & $14.21^{*}$ & 8.51 & 52.78 \\
2Dw-5-21-1 & 37.85 & 43.89 & 60.68 & 72.13 & 7.61 & 3.48 & 51.61 \\
2Dw-5-24-1 & 37.85 & 44.89 & 60.68 & 72.13 & $13.81^{*}$ & 6.18 & 63.21 \\
2Dw-5-26-1 & $49.61^{*}$ & 41.89 & 59.68 & 72.13 & $15.51^{*}$ & 3.88 & 63.21 \\
2Dw-5-28-1 & $56.67^{*}$ & 43.29 & 59.68 & 69.13 & $14.11^{*}$ & 4.48 & 62.61 \\
2Dw-5-29-1 & $76.67^{*}$ & 39.89 & 58.68 & 72.13 & $12.81^{*}$ & 6.88 & 57.91 \\
2Dw-6-3-1 & $61.67^{*}$ & 38.29 & 57.68 & 69.13 & $15.01^{*}$ & 7.18 & 63.61 \\
2Dw-6-5-1 & 46.67 & 40.59 & 57.68 & 69.13 & $14.61^{*}$ & 4.48 & 64.21 \\
2Dw-6-16-1 & 31.45 & 38.59 & 57.68 & 69.13 & $13.11^{*}$ & 6.88 & 62.91 \\
2Dw-6-17-1 & 37.58 & 42.29 & 60.68 & 72.13 & $12.31^{*}$ & 3.48 & 60.91 \\
3Dw-6-27-1 & 28.00 & 51.35 & 67.91 & 82.46 & $11.98^{*}$ & 11.07 & 69.01 \\
Alibey (K) & 54.86 & 75.10 & 91.79 & 101.43 & 8.81 & 13.74 & 68.25 \\
Ab-1-7-2 & 44.67 & 46.85 & 69.24 & 77.13 & 6.11 & 10.77 & 46.01 \\
Ab-2-14-1 & 34.67 & 46.85 & 69.24 & 77.13 & 3.91 & 11.07 & 47.01 \\
Ab-3-3-1 & $68.67^{*}$ & 46.85 & 69.24 & 77.13 & 7.71 & 8.64 & 47.61 \\
Ab-3-3-2 & 48.67 & 43.85 & 69.24 & 77.13 & 4.91 & 8.24 & 46.61 \\
Ab-3-16-1 & 54.67 & 43.85 & 70.24 & 77.13 & 5.91 & 8.24 & 48.31 \\
Selayar (k) & 60.86 & 65.55 & 85.17 & 94.48 & 8.38 & 12.19 & 63.65 \\
S1-2-14-2 & 19.67 & 58.15 & 70.24 & 80.13 & 3.21 & 8.24 & 46.31 \\
S1-3-1-1 & 24.67 & $69.45^{*}$ & 87.24 & 96.13 & $9.21^{*}$ & 8.74 & 52.61 \\
S1-3-2-1 & 18.96 & 62.85 & 85.94 & 95.13 & 3.41 & 8.74 & 53.31 \\
S1-3-2-2 & 20.46 & 58.15 & 70.24 & 82.13 & 6.21 & 8.14 & 39.31 \\
\hline Diff & D. & &
\end{tabular}

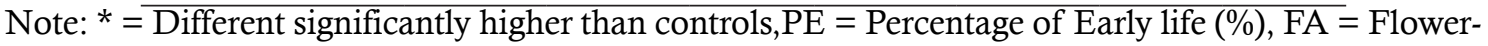
ing Age (days), RA = Ripening Age (days), HA= Harvest Age (days), LSP = Long Stem Panicle (cm), $\mathrm{PSL}=$ Panicles Stem Length $(\mathrm{cm}), \mathrm{PH}=$ PlantHeight $(\mathrm{cm})$. 
character of the initial growth (8 mutants), flowering time (1 mutant), and stem length of the panicle (15 mutants). There was no significant effect on the characters of ripening time, harvest, panicle length and plant height (Table 2). In this case, the stem length had the most mutants, namely, 15 mutants. Significant effects indicated the difference between the control and mutant plants. This study was in line with the results of the report by Setyowati et al., (2009), which stated that in 65 wheat germplasm accessions there were three characters that had a significant effect on the wheat crop: the number of tillers, the number of panicles, and the number of panicle stems.
The results of variance analysis of augmented agronomic characters of yield components showed a significant effect on the characters of number of panicles (7 mutants), number of grains per panicle (8 mutants), grain weight per observation (8 mutants), grain weight per genotype (6 mutants), leaf area (2 mutants) and leaf greenness ( $5 \mathrm{mu}-$ tants) (Table 3).

In Tables 2 and 3 (the last number on each genotype is the number of the panicles harvested) showed that the panicles often harvested were those marked the 1st (as many as 18 genotypes), namely: Dw-2-13-1, Dw-1-17-1, Dw-1-21-1, 2Dw-5-21-1, 2Dw-5-24-1, 2Dw-5-26-1, 2Dw-5-

Table 3. Character agronomic yield components in wheat mutant Dewata, Selayar and Alibey planting in BB-BIOGEN experimental garden, Sukabumi ( $\pm 450 \mathrm{~m}$ asl).

\begin{tabular}{lccccccc}
\hline Genotipe & NT & NP & NGP & GWP & SWG & LA & LG \\
\hline Dewata (K) & 25.88 & 8.89 & 3.16 & 0.10 & 4.59 & 25.87 & 52.53 \\
Dw-1-22-3 & 6.67 & 3.48 & $6.22^{*}$ & $0.20^{*}$ & $8.65^{*}$ & 2.79 & 38.49 \\
Dw-2-13-1 & 5.67 & 2.48 & 0.22 & 0.10 & $5.80^{*}$ & 2.79 & 38.09 \\
Dw-2-13-2 & 6.67 & 4.08 & 0.72 & 0.10 & $16.51^{*}$ & 2.79 & 37.29 \\
Dw-2-19-3 & 5.67 & 3.78 & $6.22^{*}$ & $0.20^{*}$ & $6.54^{*}$ & 2.79 & 44.49 \\
Dw-1-17-1 & 5.67 & 3.78 & $7.72^{*}$ & $0.30^{*}$ & $5.75^{*}$ & 2.79 & 38.79 \\
Dw-1-21-1 & 4.67 & 2.78 & 0.22 & 0.10 & $6.99^{*}$ & 2.79 & 40.69 \\
2Dw-5-21-1 & 3.71 & 2.68 & $4.22^{*}$ & $0.20^{*}$ & 0.90 & 2.51 & 44.25 \\
2Dw-5-24-1 & 7.41 & 6.38 & 0.58 & 0.10 & 0.54 & 2.51 & 45.55 \\
2Dw-5-26-1 & 4.41 & 3.38 & 0.22 & 0.10 & 0.84 & 2.51 & 34.05 \\
2Dw-5-28-1 & 5.71 & 4.68 & $6.22^{*}$ & $0.20^{*}$ & 1.26 & 2.51 & 32.35 \\
2Dw-5-29-1 & 8.01 & 6.98 & 1.72 & 0.10 & 0.68 & 2.51 & 34.05 \\
2Dw-6-3-1 & 6.01 & 4.98 & 0.58 & 0.10 & 2.36 & 15.69 & 40.85 \\
2Dw-6-5-1 & 5.41 & 4.38 & $4.22^{*}$ & $0.20^{*}$ & 1.57 & 2.51 & 45.15 \\
2Dw-6-16-1 & 6.71 & 5.68 & $12.72^{*}$ & $0.40^{*}$ & 3.02 & 2.51 & 39.95 \\
2Dw-6-17-1 & 4.71 & 3.68 & 0.58 & 0.10 & 0.98 & 2.51 & 35.15 \\
3Dw-6-27-1 & 13.07 & $9.01^{*}$ & 1.49 & 0.10 & 1.50 & 4.25 & 48.04 \\
Alibey (K) & 23.40 & 9.70 & 5.72 & 0.10 & 5.93 & 21.47 & 52.58 \\
Ab-1-7-2 & 9.07 & 8.67 & $6.00^{*}$ & $0.20^{*}$ & 1.08 & 13.52 & 49.04 \\
Ab-2-14-1 & 11.37 & $11.37^{*}$ & 0.50 & 0.10 & 0.34 & 3.98 & $55.94^{*}$ \\
Ab-3-3-1 & 10.67 & $11.37^{*}$ & 0.30 & 0.10 & 0.29 & 3.98 & $55.24^{*}$ \\
Ab-3-3-2 & 9.37 & $10.07^{*}$ & 0.20 & 0.10 & 0.24 & 3.98 & $55.54^{*}$ \\
Ab-3-16-1 & 10.67 & $12.37^{*}$ & 1.00 & 0.10 & 0.29 & 3.98 & 50.24 \\
Selayar (k) & 22.18 & 9.19 & 5.76 & 0.10 & 7.89 & 21.52 & 53.20 \\
S1-2-14-2 & 9.07 & 5.67 & 0.40 & 0.10 & 0.24 & 3.98 & $54.84^{*}$ \\
S1-3-1-1 & 12.67 & $13.37^{*}$ & 0.30 & 0.10 & 0.24 & 3.98 & $53.44^{*}$ \\
S1-3-2-1 & 14.67 & $9.67^{*}$ & 0.30 & 0.10 & 0.24 & $21.92^{*}$ & 50.14 \\
S1-3-2-2 & 11.07 & 5.37 & 0.20 & 0.10 & 0.24 & $21.72^{*}$ & 47.34 \\
\hline Diffent
\end{tabular}

Note: $*=$ Different significantly higher than controls, NT $=$ number of tillers, NP $=$ number of panicle, $\mathrm{NGP}=$ number of grains per panicle, GWP = grain weight per panicle $(\mathrm{g}), \mathrm{SWG}=$ seed weight per genotype $(\mathrm{g}), \mathrm{LA}=$ leaf area $(\mathrm{cm}), \mathrm{LG}=$ leaf greenness. 
28-1, 2Dw-5-29-1, 2Dw-6-3-1, 2Dw-6-5-1, 2Dw6-16-1, 2Dw-6-17-1, 3Dw-6-27-1, Ab-2-14-1, Ab-3-3-1, Ab-3-16-1, S1-3-1-1, and S1-3-2-1. The panicles marked the 2nd consisted of 5 genotypes, namely, Dw-2-13-2, Ab-1-7-2, Ab-3-3-2, S12-14-2, and S1-3-2-2. The panicles marked the 3rd consisted 2, namely, Dw-1-22-3 and Dw-2-19-3. This showed that the first panicles were not the only ones to harvest, but it could be the second panicles and the third panicles. However, the rest of the panicles, the fourth and so on did not have the potential to be harvested (selection method of pedigree). The potential genotypes to be harvested were those which had longer panicle stems and panicles compared to the control and had pithy grains.

Flowering age had a lower value when compared with the control plants of Dewata, Selayar and Alibey. Research in several other areas in Indonesia proved that the wheat of tropical lowland could flower faster, that is, 35-51 HST compared with plateau wheat (Aqil et al., 2011). The plants that are sensitive to changes in temperature, such as wheat, the decline in the harvest may be very sharp if the plant is planted at a lower altitude with a higher temperature and will have an affect on a significant decline in the number of flowers and the decline in the number of grains per plant (Korte et al., 1983; Handoko, 2007).

Correlation which is expressed in correlation analysis is to measure the degree of closeness of the relationship of more than two characters. Correlation analysis between the characters of growth and yield components of wheat mutants showed that grain weight per genotype was positively correlated with the percentage of the harvest growth, ripening time, harvest time, panicle length, plant height, number of tillers, number of panicles, number of grains per panicle, weight of 100 grains, grain weight per observation, but not positively correlated with flowering time and stem panicle length (Table 4). This showed that an increase in the value of these characters would influence the increase in grain weight per genotype. The grain weight per genotype was then used as the selection for M4 generation.

Correlation analysis between the component characters of mutant wheat yield of Dewata, Selayar and Alibey can be seen in Table 4. The number of tillers were positively correlated with the number of panicles, number of grains per panicle, grain weight per observation, weight of 100 grains, grain weight per genotype and leaf greenness, except the character of leaf area which was negatively correlated. This stated that the higher the characters, the more the number of tillers. The highest number of tillers in Dewata was on the genotype of 2Dw-1-27-2, while in Selayar on the genotype of S1-3-2-2 in Alibey on the genotype of Ab-3-16-1.

The performance of panicle length and flag leaf greenness which had opened up perfectly and stayed green when harvesting M3 plants grown in BIOTROP is shown in Figure 1. The performance of M3 plants had greenness and flag which were different between the control and mutant plants. Leaf greenness can be measured using SPAD-502. The higher the figure is legible in SPAD-502, the higher the percentage of chlorophyll in the leaf. According to Jangpromma et al, (2010) the reading with SPAD-520 chlorophyll meter was an interpretation of the content value of the green substance or leaf chlorophyll in plants. The study results showed that there were differences in the green colors of the leaves in the

Table 4. Correlation analysis between agronomic characters crop growth and grain yield components of the Dewata, Selayar and Alibey generation M3 Experimental Garden BB-BIOGEN, Sukabumi, in 2013.

\begin{tabular}{|c|c|c|c|c|c|c|c|c|c|c|c|c|c|}
\hline & $\mathrm{PE}$ & $\mathrm{FA}$ & $\mathrm{RA}$ & $\mathrm{HA}$ & LSP & PSL & $\mathrm{PH}$ & NT & NP & NGP & SWG & LA & LG \\
\hline $\mathrm{BGA}$ & 0.305 & & & & & & & & & & & & \\
\hline MSK & 0.200 & $0.955^{4 *}$ & & & & & & & & & & & \\
\hline PNN & 0.237 & $0.972 * \psi$ & $0.987 *$ & & & & & & & & & & \\
\hline PTM & 0.342 & $0.432 *$ & $0.494 * 4$ & $0.449 * 4$ & & & & & & & & & \\
\hline BBG & 0.233 & 0.058 & 0.040 & 0.063 & 0.3864 & & & & & & & & \\
\hline TT & 0.191 & 0.216 & 0.152 & 0.216 & $0.566 * 4$ & 0.147 & & & & & & & \\
\hline $\mathrm{JA}$ & 0.044 & $0.893 * 4$ & $0.916 * *$ & $0.917 * *$ & $0.387 *$ & 0.058 & 0.339 & & & & & & \\
\hline $\mathrm{MM}$ & 0.079 & $0.543 * 4$ & $0.656 * 4$ & $0.623 * *$ & $0.602 *$ & 0.364 & 0.057 & $0.638 * 4$ & & & & & \\
\hline JBM & 0.165 & 0.081 & 0.090 & 0.098 & 0.213 & 0.243 & 0.283 & 0.030 & 0.193 & & & & \\
\hline BBP & 0.022 & 0.359 & 0.363 & $0.377 \star$ & 0.258 & 0.092 & 0.063 & 0.334 & 0.330 & $0.879 *$ & & & \\
\hline BBG & 0.233 & 0.058 & 0.040 & 0.063 & 0.3864 & 1.000 & 0.147 & 0.058 & 0.364 & 0.243 & 0.92 & & \\
\hline LD & 0.097 & $0.739 * 4$ & $0.735 * 4$ & $0.747 * *$ & 0.330 & 0.031 & 0.202 & $0.781 * 4$ & 0.315 & 0.113 & 0.266 & 0.031 & \\
\hline $\mathrm{KD}$ & 0.233 & $0.620 * *$ & $0.681 * *$ & 0.641 & 0.776 & 0.277 & 0.220 & $0.634 * 4$ & 0.765 & 0.196 & 0.313 & 0.277 & 0.411 \\
\hline
\end{tabular}

Note: $\mathrm{PE}=$ percentage of early life $(\%), \mathrm{FA}=$ flowering age (days), $\mathrm{RA}=$ ripening age (days), $\mathrm{HA}=$ harvest age (days), LSP = long stem panicle $(\mathrm{cm}), \mathrm{PSL}=$ panicles sten length $(\mathrm{cm}), \mathrm{PH}=$ plant height $(\mathrm{cm}), \mathrm{NT}=$ number of tillers, NP = number of panicle, NGP = number of grains per panicle, GWP $=$ grain weight per panicle $(\mathrm{g}), \mathrm{SWG}=$ seed weight per genotype $(\mathrm{g}), \mathrm{LA}=$ leaf area $(\mathrm{cm}), \mathrm{LG}=1$ eaf greenness., ${ }^{*}$ and $* *=$ Correlated real at a level of $95 \%$ and $99 \%$. 
five mutants (Ab-2-14-1, Ab-3-3-1, Ab-3-3-2, S13-1-1 and S1-3-2-1) compared with controls. The green color of the leaves in mutants was darker compared to the control and other mutants. The darker green color indicated that it had a higher chlorophyll content and the character of the stay green which was positively correlated with the value of grain weight per genotype. In other words, any increase in the value of the green leaf would indicate the increase in the character of the value of grain weight per plant. It could be interpreted that the higher the value of the green leaf of wheat mutant plant, the greater the photosynthesis and the longer the stay green until the harvest, the heavier the grain weight in plants.

The decline in the rate of photosynthesis resulted in the decrease in all yield components and limited the formation of number of pods and grain filling (Baheshti \& Fard, 2010). According to Nur et al. (2012) the evaluation results of several introduction strains on the lowlands indicated that to obtain wheat genotype candidates for lowland it required a plant idiotype with many productive tillers and panicles, and broad leaf area.

The appearance of the characters which had significant differences indicated that there was a fairly wide diversity among mutants that provided the opportunity to produce the desired mutants. Agronomic characters with good performance indicated tolerant to tropical mediumhigh plains and allowed for the re-selection of M4 in medium land. The combinations of temperature and humidity, irradiation period and irradiation intensity, and high rainfall added to the level of stress on the growth and development of the wheat plants.
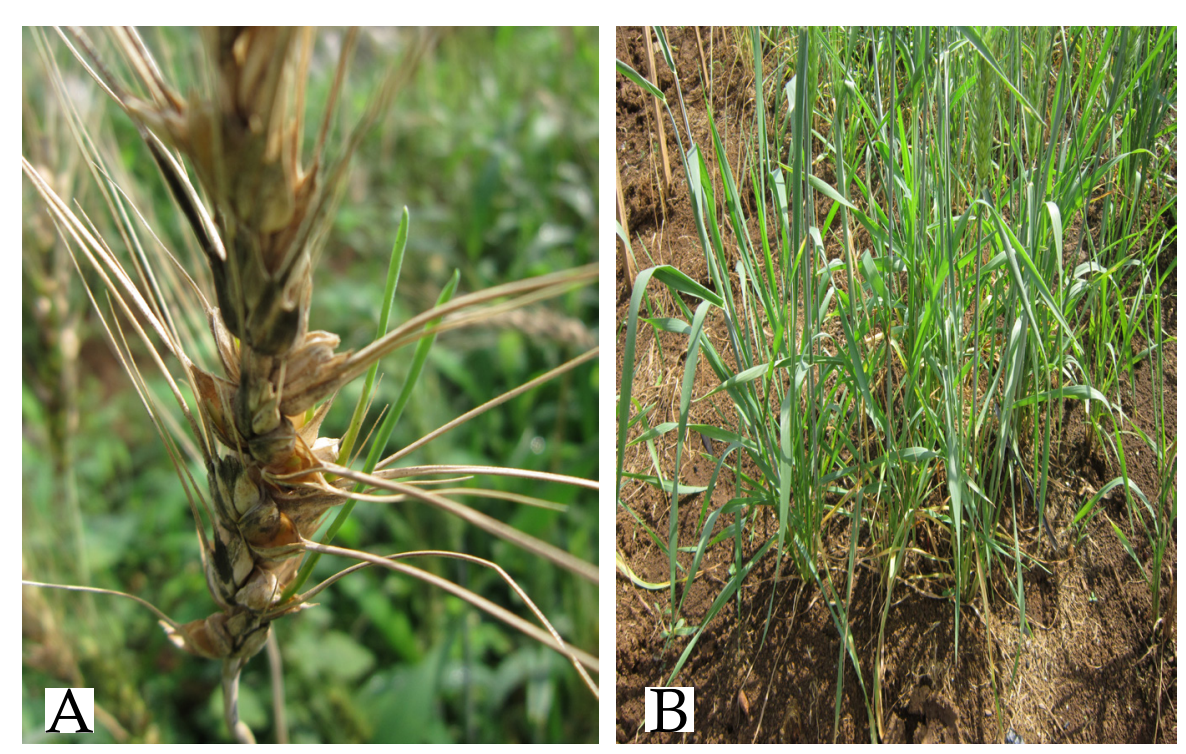

Figure 2. The phenomenon happens on the field, A). Seeds germinated wheat (tolerant); B) Leaves roll due to high temperature stress (tolerant).

Figure 1. Performance of panicle length and flag leaf greenness M3 plants in the Experiments Garden BB-BIOGEN ( $\pm 450 \mathrm{~m}$ asl). (= The flag leaf).

Leaf color in harvest time could be used as an indicator that the plant was feasible to be selected for planting the next generation. The flag leaves that remain green at the time of harvest indicated that the leaves had stay green properties since the color was closely related to the capacity of the source and the accumulation of carbohydrates in the stem and leaf flag.

The phenomenon that occurred in the field at harvest time was wheat grains which were harvested late germinated one day after the rain fell and leaves rolled due to the temperature stress (Figure 2). Harvesting wheat cannot be done at the same time just like harvesting rice crop. Har-

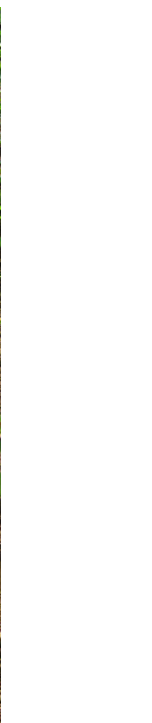


vesting wheat is done in stages, where the first panicles are first harvested, continued with second panicles, and so on. To calculate how many days are needed to determine the age of the harvest, that is, the number of days from planting to the time when more than $50 \%$ of the crop had yellow panicles in each plot. Sprouting is the germination of wheat grains in the panicle because harvest is done beyond the harvest period. This is influenced by the grain dormancy time, and the climatic factor such as a high temperature in the process of grain filling which falls at the period of dormancy (Gavazza et al, 2012). The results of this study have the same phenomenon when grown in lowland SEAMEO-BIOTROP, Bogor $( \pm 250$ $\mathrm{m}$ asl) that will germinate when the panicle late harvest and the leaves will curl in the plant stress tolerance for high temperatures (Sari et al., 2015).

One of the obstacles encountered in Indonesia, namely the absence of adaptive varieties in the middle plains and high temperature stress. The need for wheat genetic improvement of tropical origin, thereby reducing the import of wheat to Indonesia. The results of this study produces some mutant wheat is expected to produce wheat plants that can adapt and produce in the tropics, especially Indonesia

\section{CONCLUSION}

Agronomic growth characters showed a significant effect on the percentage of the initial growth, flowering time, stem panicle length, number of panicles, number of grains per panicle, grain weight per observation, grain weight per genotype, leaf area and leaf greenness. Mutants of Dewata, Selayar and Alibey could be selected based on such characters as panicle stem length, number of grains per panicle and grain weight per observation because the characters generated more mutants compared to the other characters. Correlation analysis between the characters of growth and yield components of wheat mutants showed that the number of grains per panicle was positively correlated with grain weight per observation, while the length of the stem panicle was positively correlated with grain weight per genotype, number of panicles and leaf area. Number of panicles and leaf area was positively correlated with leaf greenness character. High temperature stress is one of the limiting factors that affect the growth and production of crops for causing reduced yield potential.

\section{ACKNOWLEDGEMENTS}

The authors thanks to: (1). Prof. Dr. I Made Sudiana M.Sc for kindly providing our manuscrip, also for the Nasional Training, Education Center for Researcher Development-LIPI. (2). Head of ICABIOGRAD for the permition and facilities to this research, (3). DIPA ICABIOGRAD for wheat field test 2013-2014.

\section{REFERENCES}

Aptindo. (2012). http://bataviase.co.id/node/436332. [Desember 2012].

Aqil, M., Marcia, B. P., \& Muslimah, H. (2011). Innovation adaptive wheat plains (bahasa). Majalah Sinar Tani, Edisi 3390, 12-13

Beheshti, R. A., \& Fard, B. B. (2010). Dry matter accumulation and remobilization in grain sorghum genotypes (Sorghum bicolor L. Moench) under drought stress. Australian Journal of Crop Science, 4(3), 185-189.

Carver, B. F. (2009). Wheat Science and Trade. Edition First. USA: Wiley Blacwell Publishing.

Dahlan, M., Rudijanto., Murdianto, J., \& Yusuf, M. (2003). Proposed Release of Wheat Varieties. Cereal Crops Research Institute and Agricultural development. Jakarta: Badan Penelitian dan Pengembangan Pertanian.

Das, A., Gosal, S. S., Sidhu, J. S., \& Dhaliwal, H. S. (2000). Induction of mutations for heat tolerance in potato by using in vitro culture and radiation. Euphytica, 114(3), 205-209.

Gavazza, M. I. A., Bassoi, M. C., Carvalho, T. C. D., Bespalhok Filho, J. C., \& Panobianco, M. (2012). Methods for assessment of pre-harvest sprouting in wheat cultivars. Pesquisa Agropecuária Brasileira, 47(7), 928-933.

Handoko, I. (2007). Gandum 2000. Research and Development of Wheat in Indonesia. SEAMEOBiotrop. Bogor. Indonesia. p.118.

Jangpromma, N., Songsri, P., Thammasirirak, S., \& Jaisil, P. (2010). Rapid assessment of chlorophyll content in sugarcane using a SPAD chlorophyll meter across different water stress conditions. Asian Journal of Plant Sciences, 9(6), 368-374.

Korte, L. L., Specht, J. E., Williams, J. H., \& Sorensen, R. C. (1983). Irrigation of soybean genotypes during reproductive ontogeny II. Yield component responses. Crop Science, 23(3), 528-533.

Micke, A., \& Donini, B. (1993). Induced mutations. In Plant Breeding (pp. 52-62). Netherlands: Springer.

Nur, A., Trikoesoemaningtyas., Khumaida, N., \& Yahya, S. (2012). Evaluation And Genetic Diversity strain Introductions Wheat (Triticum aestivum L) On Tropical Agroekosistem. J. Agrivigor., 11(2), 230-243.

Petersen, R. G. (1994). Agricultural Field Experiments, Design and Analysis. New York: Marcel 
Dekker Inc.

Sakin, M. A. (2002). The use of induced Micro Mutation for Quantitative Characters after EMS and Gamma ray Treatments in Durum Wheat Breeding. Pakistan Journal of App.Science, 2(12), 1102-1107.

Sari, L., Purwito, A., Sopandie, D., Purnamaningsih, R., \& Sudarmonowati, E. (2014). InVitro Selection of Wheat(Triticum Aestivum) Mutants Tolerant on Lowland. International Journal of Agronomy and Agricultural Research, 5(5), 189199.

Sari, L., Purwito, A., Sopandie, D., Purnamaninfsih, R., \& Sudarmonowati, E. (2015). The morphology, anatomy and physiology characterization of mutant wheat (Triticum aestivum) "Alibey" in tropical lowland area. Journal of Biodiversity and Environmental Sciences, 6(1), 385-403.

Setyowati, M., Hanarida, I., \& Sutoro. (2009). Grouping of germplasm of wheat (Triticum aestivum) based on quantitative characters of plants (ba- hasa). Buletin Plasma Nutfah, 15(1), 25-37.

Soeranto, H., Nakanishi, T. M., \& Razzak, T. M. (2003). Obtaining induce mutation of drought tolerance in Sorghum. Radioisotop Journal, 52(1), 15-21.

Sopandie, D. (2013). Adaptation Physiology of Plants to Abiotic Stress on Agroekosistem Tropika. Bogor: IPB Press.

Van Harten, A. M. (1998). Mutation Breeding: Theory and Practical Applications. New York: Cambridge University.

Van Ginkel, M., \& Villareal, R. L. (1996). Triticum L., In Grubben GJH, Partohardjono S.(Eds.). Plant resourse of South-East Asia (PROSEA), No.10. Cereals. Leiden: Backhuys Publisher.

Viswanathan, P., \& Reddy, V. R. K. (1996). Genetics of early flowering mutans in triticale. Acta Agronomica Hungaria, 46(4), 389-391.

Wiyono, N. T. (1980). Wheat Cultivation (Triticum sp. (bahasa)). Jakarta: PT. Karya Nusantara. 